\title{
Synthesis of silver nanoparticles and the antibacterial and anticancer activities of the crude extract of sargassum polycystum C. Agardh
}

\author{
Nallamuthu Thangaraju* ${ }^{1}$ and Ramanujam Prasanna Venkatalakshmi ${ }^{1}$, Arulvasu Chinnasamy ${ }^{2}$, Pandian Kannaiyan $^{3}$ \\ ${ }^{1}$ Centre for Advanced Study in Botany, School of Life Sciences, University of Madras, Guindy Campus, Chennai - 600025 \\ ${ }^{2}$ Department of Zoology, University of Madras, Guindy Campus, Chennai - 600025. \\ ${ }^{3}$ Department of Inorganic Chemistry, University of Madras, Guindy Campus, Chennai - 600025.
}

* Corresponding author: nthangam@gmail.com(N. Thangaraju)

Tel/fax.:+91-4422352494 / 22353309

\begin{abstract}
The potential of the methanolic extract of the seaweed, Sargassum polycystum in the synthesis of silver nanoparticles was investigated. The extract synthesized appreciable quantities of silver nanoparticles of the size $5-7 \mathrm{~nm}$, in 24 hrs. The particles were characterized by UV-Vis, FT-IR spectroscopy, HRTEM and XRD analysis. The results indicated that the algal extract can be utilized as an eco-friendly system for the synthesis of silver nanoparticles for various applications in the field of medicine. The methanolic extract of the alga, silver nitrate solution and their combination were tested for their antimicrobial activities against Pseudomonas aeruginosa, Klebsiella pneumoniae, Escherichia coli and Staphylococcus aureus. Anticancer activity of the extract and the silver nanoparticles were evaluated against the breast cancer line MCF-7. Active compounds in the crude extract of the alga were separated and identified as fatty acids by GC-MS analysis. These fatty acids together with the silver nanoparticles exhibited anticancer activity against the breast cancer cell line MCF-7. Results are presented and discussed in detail.
\end{abstract}

Keywords: Sargassum polycystum C. Agardh, Brown Alga, Silver Nanoparticles, Antimicrobial Activity and Anticancer Activity.

Citation: N. Thangaraju, et al. Synthesis of silver nanoparticles and the antibacterial and anticancer activities of the crude extract of sargassum polycystum c. Agardh. Nano Biomed. Eng. 2012, 4(2), 89-94.DOI: 10.5101/nbe.v3i1.p89-94.

\section{Introduction}

One of the major developments in Nanotechnology is the production and application of Nanoparticles in biology. Nanoparticles of free metals have been extensively researched because of their unique physical properties, chemical reactivity and potential applications in catalysis, biological labeling, biosensing, drug delivery, antibacterial activity, antiviral activity, detection of genetic disorders, gene therapy and DNA sequencing [6] A great amount of hazardous and unwanted chemicals, substances, is an increasing alarming environmental pollution which causes damaging our ecosystem so now it is our need to learn about the inherently present in the nature and its products, lead to the development of Biomimetic approaches for the growth of advancements in the synthesis processes of Nanoparticles [15].

Among various nanoparticles which have found commercial applications, the silver nanoparticles find several applications, like antimicrobial, anticancer, optoelectronics, recording media, sensing devices, catalysis, medicine, semi conductors etc., Owing to extremely small size, silver nanoparticles exhibit enhanced properties when compared with the bulk material. This includes those having large surface area relative to their volume, ability to easily interact with other particles and increased antibacterial efficiency [13].

Silver nanoparticles are the metal of choice as they hold the promise to kill microbe's effectively. The silver nanoparticle act on a broad range of target sites both extracellularly as well intracellularly. In fact microbes generally have a harder time developing resistance to silver than they do to antibiotics. Silver nanoparticles take advantages of the oligodynamic effect that silver has on microbe, whereby silver ions bind to reactive groups in bacterial cells, resulting in their precipitation and inactivation [16]. Concerning the biological application of Nanoparticles it has been emphasized that methods of 
synthesis through biological system via, micro-organisms including bacteria, yeasts, fungi and diatoms synthesizing inorganic materials either intra or extracellularly would make the nanoparticles more biocompatible [6].

There is hence an unequivocal need to develop more cost - effective and environmental benign ("green chemistry") alternatives to these existing methods. The choice of an environmentally compatible solvent system, an eco-friendly reducing agent, and a nonhazardous capping agent for the stabilization of the nanoparticles are three main criteria for a totally "green" nanoparticles synthesis. For these reasons researchers in the field of nanoparticle synthesis turn to the biological systems where many organisms, both unicellular and multicellular, are known to produce inorganic nanostructures even though the actual mechanisms are not yet known because of the complexity of most biological reactions [8].

Some well known examples are synthesis of gold nano triangles by using Lemon grass extract and tamarind leaf extract [3,11]. Geranium leaf assisted biosynthesis of silver nanoparticles [10]. Synthesis of silver nanoparticles using fungus $[1,9]$.Synthesis of silver nanoparticle by a silver tolerant yeast strain MKY3 [7]. Synthesis of $\mathrm{Au}, \mathrm{Ag}$ and bimetallic. Au core-Ag shell nanoparticles using Neem leaf broth [12]. Biosynthesis of silver based crystalline nanoparticles of well defined composition and shapes within the periplasmic space of bacteria Pseudomonas stutzery AG259 isolated from silver mines [14]. Synthesis of silver nanoparticles by reducing Silver Nitrate Solution by the extract of Mentha Piperita Leaves [15].The synthesis of silver nanoparticles using Marine algae have been unexplored, which aroused our interest in the present investigation. Since marine algae are rich source of dietary fiber, minerals, proteins and vitamins .

The uses of marine algae include traditional cosmetics, as antipyretic and antiseptic compounds, vermifuges and as treatments for sunstroke, coughs, hemorrhoids, stomach ailments, nose-bleeds, goiter and urinary diseases [1].

\section{Material and methods}

\section{Chemicals}

The solvents ethyl acetate, acetone and methanol were purchased from Sisco Research Laboratories (Mumbai, India).Agar, Peptone, Yeast Extract and Dextrose were purchased form HiMedia (Mumbai, India). Dulbecco's Modified Egals's Medium (DMEM), Fetal Bovine Serum (FBS), Trypsin-EDTA, 3-(4, 5-dimethylthiazol-2yl)-2, 5diphenyltetrazolium bromide (MTT) were purchased from Sigma (St. Louis, USA). Sodium bicarbonate, Dimethyl sulphoxide (DMSO) and antibiotic cocktail solution were purchased from HiMedia (Mumbai, India). The other chemicals and reagents were used in this study were of analytical grade.

\section{Collection of seaweeds}

Sargassum polycystum belonging to the Phaeophyta division was collected from the Gulf of Mannar, Rameshwaram, Tamil Nadu, India. The seaweed sample was washed in seawater and then fresh water to remove the epiphytes and other contamination.

\section{Extraction of seaweed}

The coarsely powdered seaweed material (100 g) was extracted with $(400 \mathrm{~mL})$ of methanol for 5 days at room temperature with shaking condition. The crude extract was filtered and concentrated by rotary evaporator. About $0.3 \mathrm{~g}$ of crude extract dissolved in $50-60 \mathrm{~mL}$ of deionized water, followed by the immediate addition of $1 \mathrm{M} \mathrm{AgNO}_{3}$ of different concentration $(0.2,0.4,0.6$ and $0.8 \mathrm{~mL}$ ). The $\mathrm{pH}$ of the reaction medium was adjusted by adding $0.2 \mathrm{ml}$ of $\mathrm{NH}_{3}$ solution. The reaction was carried out at room temperature for $24 \mathrm{~h}$.

\section{UV-Vis Spectrophotometer}

UV-Vis spectrophotometer experiment was carried out on a Shimadzu UV-8500 PC scanning spectrometer using $\mathrm{AgNO}_{3}$ as the reference. 2-3 drops of the sample was pipetted into quartz UV Cell $(2 \mathrm{ml})$ and diluted with deionized water, followed by immediate spectral measurements. Deionized water was used as blank for all measurements.

\section{Fourier Transform Infrared (FT-IR) Spectroscopy}

The chemical composition of the seaweed was characterized by FT-IR (Bruker Tensor 27). $1 \mathrm{ml}$ of the sample was taken in a zinc selenium liquid holder and the results were recorded.

\section{X-Ray Diffraction (XRD) analysis}

Crystallographic information of the bioreduced Silver Nitrate solution was dried. XRD patterns were recorded by a SEIFERT X-ray diffractometer with cu $\mathrm{K} \alpha$ radiation. The samples were scanned in the $2 \theta$ range of $10{ }^{\circ} \mathrm{C}-70$ ${ }^{\circ} \mathrm{C}$.

\section{Energy Dispersive X-ray (EDX) Analysis}

In order to carry out EDX analysis, the Bioreduced silver nitrate solution was dried and drop coated on to carbon film and performed on a SEM instrument equipped with EDX attachment.

\section{Transmission Electron Microscopy (TEM)}

Examination of the nanoparticle morphology by transmission electron microscopy was performed on a CM12 Philips model in SAIF, IIT Madras with an electron kinetic energy of $120 \mathrm{KV}$. For sample preparation a drop of silver solution was dispensed onto a carbon coated copper grid. 
Article

Nano Biomed. Eng

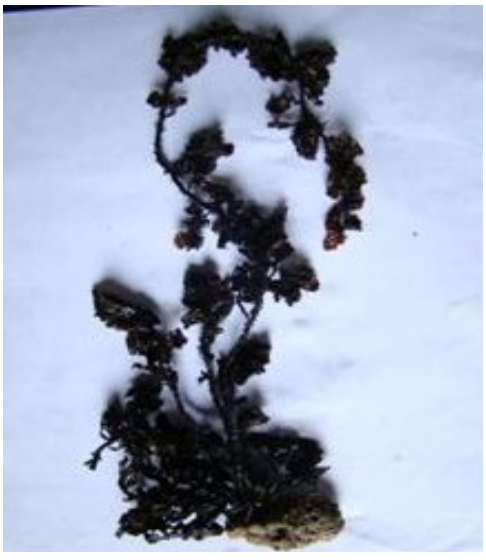

Fig. 1 S. polycystum - Brown alga

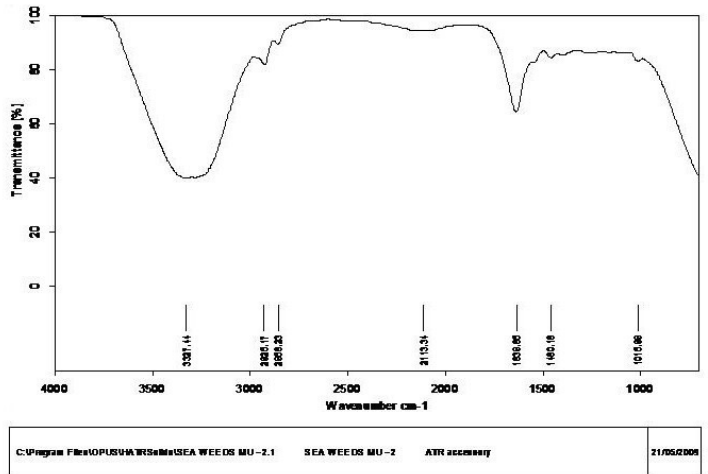

Fig. 3 FT-IR spectra of silver nanoparticles synthesized by S. polycystum

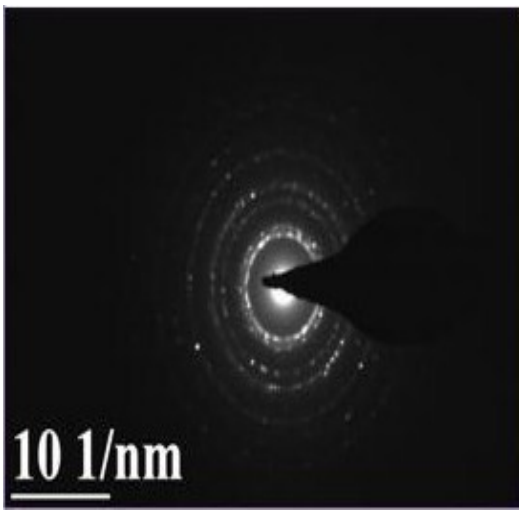

Fig. 5 SAED pattern of major silver nanoparticles formed by reduction of $\mathrm{Ag}^{+}$ions

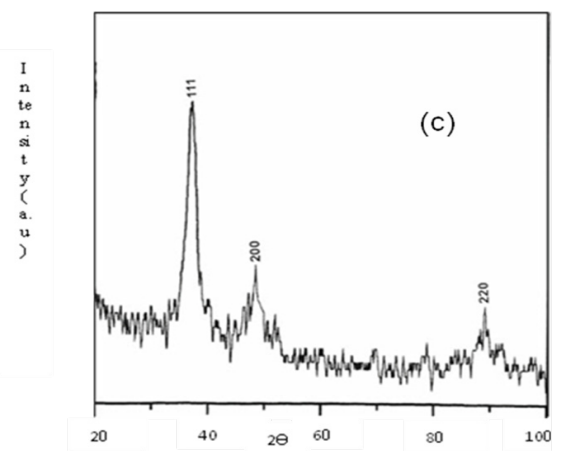

Fig. $7 \mathrm{X}$ ray diffraction pattern of silver nanoparticles using $S$. polycystum

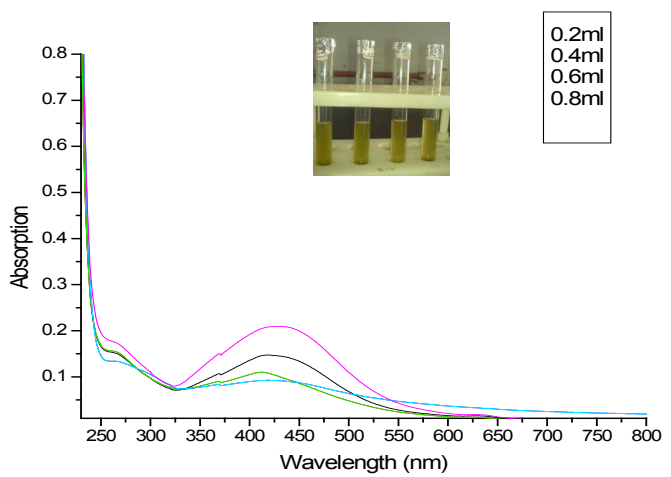

Fig. 2 Yellow color indicating the formation of silver nanoparticles. UV-Visible absorption spectra recorded at $420 \mathrm{~nm}$ for different concentrations of silver nitrate with $S$. polycystum extract.

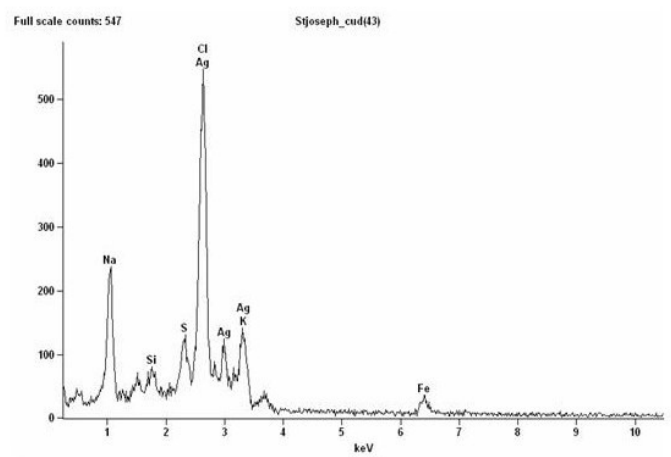

Fig. 4 EDX Profile of Silver Nanoparticles synthesized by S. polycystum

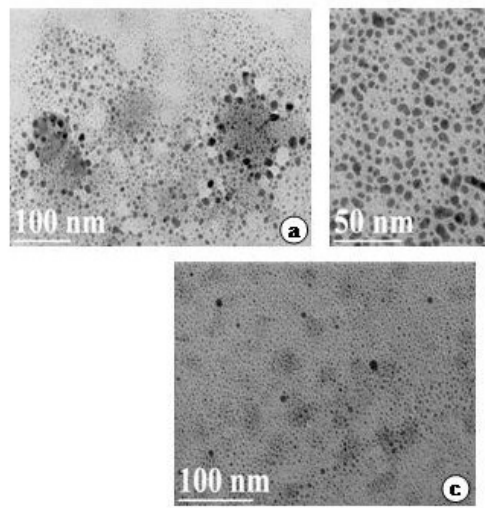

Fig. 6 a, b, c: TEM images of silver nanoparticles by S. polycystum extract ranging from $50 \mathrm{~nm}$ and $100 \mathrm{~nm}$.
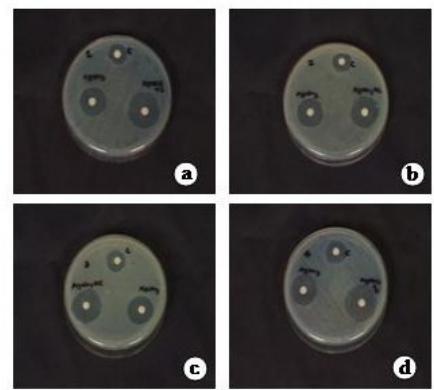

Fig. 8 Antimicrobial activities for S. polycystum extract and silver nanoparticles . a) Pseudomonas aeruginosa, b) Klebsiella pneumoniae, c) E. coli, d) Staphylococcus aureus 
Table 1. Antibacterial activity of $S$. polycystum extract

\begin{tabular}{|c|l|c|c|c|}
\hline \multirow{2}{*}{ S. No. } & \multicolumn{2}{|c|}{ Organisms } & \multicolumn{3}{|c|}{ Zone of inhibition $(\mathrm{mm})$} \\
\cline { 3 - 5 } & & $\begin{array}{l}\text { Seaweed crude } \\
\text { extract }(50 \mu \mathrm{L})\end{array}$ & $\begin{array}{l}\mathrm{AgNO}_{3} \\
(50 \mu \mathrm{l})\end{array}$ & $\begin{array}{l}\text { Seaweed crude extract } \\
\text { along with } \mathrm{AgNO}_{3}(100 \mu \mathrm{L})\end{array}$ \\
\hline 1 & Pseudomonas aeruginosa & 15 & 23 & 32 \\
\hline 2 & Klebsiella pneumoniae & 16 & 22 & 33 \\
\hline 3 & Escherichia coil & 19 & 28 & 37 \\
\hline 4 & Staphylococcus aureus & 20 & 26 & 38 \\
\hline
\end{tabular}
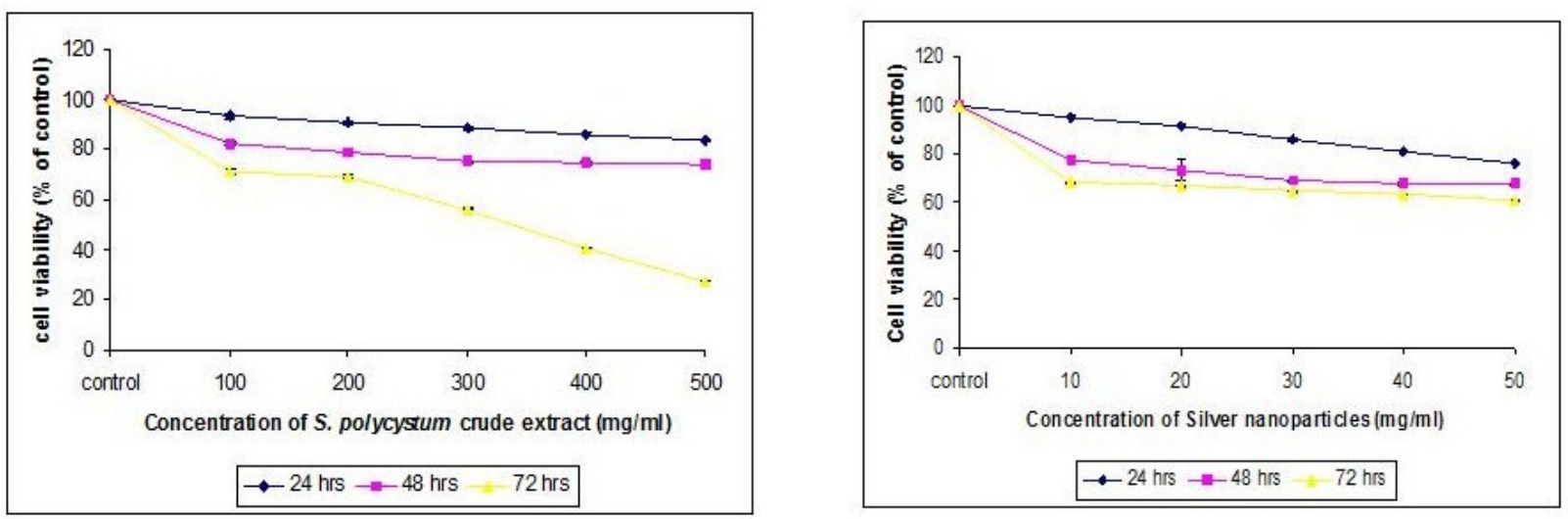

Fig. 9 Cell proliferation using MTT method of both crude extract and synthesized nanoparticles

Table 2. Extract of $S$. polycystum by chromatographic identification obtained from GC - MS.

\begin{tabular}{|l|l|}
\hline Retention time & Separated compounds \\
\hline 226.4851 & Hexadecane \\
\hline 255.4049 & Hexadecanoicacid \\
\hline 269.221 & 1 - Eicosanol - Octadecanol \\
\hline 279.9924 & Octadecanoic acid \\
\hline 284.2768 & 0ctadecane \\
\hline 169.4085 & Eicosane \\
\hline 252.1452 & Myristic acids \\
\hline 232.7779 & \\
\hline
\end{tabular}

Antimicrobial activity for Silver Nitrate, Crude Extract and their combination was done by Disc Diffusion method

The standard strains were procured from ATCC, USA and the pathological strains were procured from the microbiology, CEEAL Analytical LAB, Chennai, India. The antimicrobial activity of the Crude extract, $\mathrm{AgNO}_{3}$ before and after formation of silver nanoparticles was screened against the following bacteria.

Pseudomonas aeruginosa ATCC 1688, Klebsiella pneumoniae ATCC 11298, Escherichia coli ATCC 25922, Staphylococcus aureus ATCC 9144 on Nutrient agar 92 medium by disc diffusion method incubate the plates for $24 \mathrm{~h}$ at $37^{\circ} \mathrm{C}$ and results were recorded.

\section{Cytotoxic Activity for Crude Extract and Silver Nanoparticles}

To estimate Cell Cytotoxicity, MCF 7 Breast cancer cells were obtained from the National Centre for Cell Science (NCCS), University of Pune, were seeded $\left(1 \times 10^{4}\right)$ in 96-well plates in $100 \mu \mathrm{l}$ of $5 \% \mathrm{FBS}-\mathrm{DMEM}$ at $37^{\circ} \mathrm{C}$ in a $5 \% \mathrm{CO}_{2}$ incubator. After culturing for $24 \mathrm{~h}$, the various concentrations of crude extract and silver nanoparticles were treated and incubated for additional $24 \mathrm{~h}$ at $37^{\circ} \mathrm{C}$ in a $5 \% \mathrm{CO}_{2}$ incubator. After incubation $10 \mu \mathrm{L}$ of MTT were added to each well, and cells were then incubated for $4 \mathrm{hrs}$ at $37^{\circ} \mathrm{C}$ in a $5 \% \mathrm{CO}_{2}$. Absorbance was measured at $570 \mathrm{~nm}$.

\section{Chromatographic Identification}

Methylation or Silylation of extract was performed before injection in gas chromatography combined with mass spectrometry (GC-MS) in SAIF, IIT Madras. Total ion chromatograms and active compounds were analyzed.

\section{Results and Discussion}

The seaweed used in this study was Sargassum polycystum C. Agardh, brown alga (Fig.1) that has been characterized in a previous study. Addition of Sargassum polycystum extract to $1 \mathrm{M}$ aqueous $\mathrm{AgNO}_{3}$ solution lead to the appearance of yellowish brown colour indicating the formation of silver nanoparticles. These colors 
arise due to excitation of Surface Plasmon Vibrations in the metal nanoparticles (Fig. 2 inlet). After $24 \mathrm{~h}$ of reaction shows the UV-Vis spectra recorded from the aqueous silver nitrate- $S$. polycystum reaction medium at different concentration of the reaction medium. The silver Surface Plasmon Resonance (SPR) band occurred at $420 \mathrm{~nm}$ and steadily increased in intensity as the different concentration of reaction medium without any shift in the peak (wave-length) (Fig. 2). For all the other instrumentation, $0.8 \mathrm{ml}$ concentration was taken and analyzed. According to the protocol from Govindaraju et al., 2008, silver, gold and bimetallic nanoparticles were synthesized using the cyanobacterium Spirulina platensis. The characterization for the nanoparticles are carried out by UV, XRD, FT-IR, EDX and HRTEM were confirmed the reduction of metals. It contains various sugars, mannitol, proteins, amino acids, lipids, pigments, vitamins and inorganic salts of primarily $\mathrm{Na}^{+}, \mathrm{Ca}^{2+}, \mathrm{K}^{+}$and $\mathrm{Mg}^{2+}$. The presence of carboxylic, amine, phosphate and hydroxyl functional groups was confirmed by FT-IR measurements (Fig. 3). Fig. 4 shows the surface of silver nanoparticles and the elements present in the extract by EDX. Fig. 5 shows the Selected Area Electron Diffraction (SAED) pattern of the silver nanoparticles represented face centered cubic crystalline structure of the silver the different diffracting planes. TEM was utilized to characterize the particles and their size and distribution by taking micrograph from drop coated films of the silver nanoparticles synthesized by the treatment of silver complex solution $S$. polycystum extract. Nanoparticles observed from the micrograph majority are spherical with a small percentage of elongated particles ranged in size of $50 \mathrm{~nm}$ and $100 \mathrm{~nm}$ (Fig. 6 a, b, c). According to Parashar et al., 2009, the synthesis of silver nanoparticles using Parthenium leaf extract showed the UV spectra reading at $474 \mathrm{~nm}$ and the size of particles are ranged from 50nm in TEM analysis [17].

XRD pattern obtained for the silver nanoparticles synthesized by $S$. polycystum extract. The presence of intense peaks of nanoparticles (111), (200) and (211) appeared which are indexed as crystalline silver centered cubic phase, the XRD pattern thus clearly shows that the silver nanoparticles formed by the reduction of $\mathrm{Ag}^{2+}$ ions by $S$. polycystum extract are crystalline (Fig. 7).

Antibacterial activity of $S$. polycystum extract, silver nitrate and their combination were tested against human pathogens which mention before all the organism showed the activity the results given in the Table. 1 and Fig. 8. The similar results were recorded in the Methanolic extracts of seaweed extracts showed broad spectrum of antibacterial activity (Kandhasamy et al., 2008).

The crude extract of $S$. polycystum and silver nanoparticles showed cytotoxicity against MCF 7 breast cancer cell line in dose dependent manner. The $\mathrm{IC}_{50}$ for seaweed extract at $300 \mathrm{mg} \mathrm{mL}^{-1}$ for $72 \mathrm{~h}$ was higher than other concentration and the $\mathrm{IC}_{50}$ for Silver nanoparticles at $135 \mathrm{mg} \mathrm{mL}^{-1}$ for $72 \mathrm{~h}$ was higher than other concentration (Fig. 9). The cell proliferation was estimated using the 96 well plate MTT dye method by absorbing at $570 \mathrm{~nm}$. Each line indicates the mean \pm SD of values obtained from triplicate experiments.

Isolation and characterization of some antifouling agents from Sargassum confusum were characterized by GC-MS studies by exhibiting the compounds like hexadecane, hexadecanoicacid, cis - 9 - octadecanol, 1 - eicosanol, octadecanoic acid [4]. The results of the present study also showed similar findings (Table. 2).

\section{Conclusion}

In this study, silver nanoparticles were synthesized by using $S$. polycystum extract and characterized by UV-Vis, FT-IR, EDX, XRD and TEM techniques. The antimicrobial activity was tested against four different human pathogens. The anticancer activity was tested against MCF 7 breast cancer cell line and the bioactive compound present in crude extract was separated and its molecular mass was estimated. Thus the application of such eco-friendly silver nanoparticles in bactericidal, anticancer and other medical and electronic applications, make this method potentially exciting for the large scale synthesis of other inorganic nanomaterials. Further researches require to gain insight into the molecular mechanism involve in silver nanoparticles, its toxicity, immunity and mode of action, which is necessary for safe and effective exploitation of silver nanoparticles in biomedical, biotechnological, nanotechnology based industries.

\section{Acknowledgements}

The authors are gratefully thanking to Prof. Dr. R. Rengasamy, Director, Centre for Advanced Studies in Botany, University of Madras, for his valuable suggestions during this work.

\section{References}

1. Ahmad A, P. Mukherjee, S. Senapati, D. Mandal, M.I. Khan, Rajeev Kumar and Muraly Sastry, Extracellular biosynthesis of silver nanoparticles using the fungus Fusarium oxysporum. Colloids Surf. B. 2003; 28: 313.http://dx.doi.org/10.1016/S09277765(02)00174-1

2. Anggadiredja J, Ria Andyani, Hayati, Muawanah. Antioxidant activity of Sargassum polycystum and Laurencia obtusa from Seribu islands. Journal of Applied Phycology. 1997; 9: 477-479. http://dx.doi.org/10.1023/A:1008075625735

3. Balaprasad Ankamwar, Bio inspired synthesis of silver nanoparticles. Metal-Organic and Nano-Metal Chemistry. 2005; 3: 19. http://dx.doi.org/10.1081/SIM-200047527

4. Ganti VS, Kim KH, Bhattarai H D, Shin H W. Isolation and characterization of some antifouling agents from the brown alga Sargassum confusum. Journal of Asian Natural Products Research. 2006; 8(4): 309 - 315.http://dx.doi.org/10.1080/1028602050 0034980

5. Kandhasamy M, Arunachalam K D. Evaluation of invitro antibacterial property of seaweeds of Southeast coast of India. African Journal of Biotechnology. 2008; 7 (12): 1958-1961.

6. Kasivelu Govindaraju, Sabjan Khaleel Basha, Vijaya Kumar, Ganesh Kumar, Ganesan Singaravelu. Silver, gold and bimetallic nanoparticles production using single cell protein Spirulina platensis Geitler. Journal of Material Science. 2008; 43: 5115 - 5122. 
http://dx.doi.org/10.1007/s10853-008-2745-4

7. Meenal Kowshik, Shriwas Ashtaputre, S. Kharrazi, W.Vogel, J.Urban, S. K. Kulkarni, K.M. Paknikar, Extracellular synthesis of silver nanoparticles by a silver-tolerant yeast strain MKY3. Nanotechnology. 2003; 14: 95.http://dx.doi.org/10.1088/0957$4484 / 14 / 1 / 321$

8. Liu B, Xie J, Lee J Y, Ting Y P, Paul Chen J. Optimization of HighYield Biological Synthesis of Single-Crystalline Gold Nanoplates. Wiley online library. 2005; 36: 45. DOI: 10.1002/chin.200545219.

9. Mukherjee P., A. Ahmad, D. Mandal, S. Senapati, S. R. Sainkar, M. I. Khan, R. Parishcha, P. V. Ajayakumar, M. Alam, R. Kumar and M. Sastry. Fungus mediated synthesis of silver nanoparticle and their immobilization in the mycelial matrix: A novel biological approach to nanoparticle synthesis. Nano Lett 2001; 1: 515.http://dx.doi. org/10.1021/nl0155274

10. Shiv Shankar S, Absar Ahmad, Murali Sastry. Geranium leaf assisted biosynthesis of silver nanoparticles. Biotechnology. 2003; 19: 1627.

11. Shiv Shankar S, Akhilesh rai, Absar Ahmad, Murali Sastry. Rapid synthesis of Au, Ag and biometallic Au core-Ag shell nanoparticles using Neem leaf broth. Journal of colloid and Interface Science. 2004; 275: 496 - 499.http://dx.doi.org/10.1016/j.jcis.2004.03.003

12. Shiv Shankar S, Akhilesh rai, Balaprasad Ankamwar, Amit Singh, Absar Ahmad, Murali Sastry. Biological synthesis of triangular gold nanoprisms. Nature Materials. 2004; 3: 482-488.
13. Sreeram K J, Nidhin M, Nair B U. Microwave assisted template synthesis of silver nanoparticles. Bulletin Material Science. 2008; 31(7): 937- 942.http://dx.doi.org/10.1007/s12034-008-0149-3

14.Klaus T, R. Joerger, E. Olsson, C.G. Granqvist, Silver-based crystalline nanoparticles, microbially fabricated. Proc. Natl. Acad. Sci. U.S.A. 1999; 96(24): 13611-4.http://dx.doi.org/10.1073/ pnas.96.24.13611

15.Upendra Kumar Parashar, Preeti S. Saxena, Anchal Srinvastava. Bioinspired synthesis of silver nanoparticles. Digest Journal of Nanomaterials ad Biostructures. 2009; 4 (1): 159-166

16.Vyom Parashar, Rashmi Parashar, Bechan Sharma, Avinash C Pandey. Parthenium leaf extract mediated synthesis of silver nanoparticles: A novel approach towards weed utilization. Digest Journal of Nanomaterials and Biostructures. 2009; 4(1): 45-50.

Copyright:(c) 2012 N. Thangaraju, et al. This is an openaccess article distributed under the terms of the Creative Commons Attribution License, which permits unrestricted use, distribution, and reproduction in any medium, provided the original author and source are credited. 